\title{
Research on the Status of Traffic Safety Supervision in Henan Province Based on the Fuzzy Analytic Hierarchy Process
}

\author{
Yuchao Xiong ${ }^{1}$, Jinchao Yue ${ }^{1, *}$, Shuren $\mathrm{Li}^{2}$, Shengqi Jian ${ }^{1}$ \\ ${ }^{1}$ School of Water Conservancy Science and Engineering, Zhengzhou University, Zhengzhou, China \\ ${ }^{2}$ Bureau of henan province, Zhengzhou, China \\ *Corresponding author.Email: yuejc@zzu.edu.cn
}

\begin{abstract}
According to the actual situation of the current status of transportation safety supervision and regulatory questionnaires of Henan province, the analytic hierarchy process and the fuzzy evaluation are used in this paper to establish a hierarchical structure model of transportation safety supervision. Four indexes were consisted of in the criterion layer and twenty-five indicators were determined in the factor layer. Programs were solved using Matlab2015 software. Evaluation of the status of transportation safety supervision in Henan province was carried out. According to the rating level, the current transportation safety supervision status in Henan province is in a good statue. This study is an important reference for improving the assessment and evaluation system of transportation safety supervision departments in Henan Province, as well as promoting the further development of safety production supervision in the transportation industry in Henan Province.
\end{abstract}

Keywords: Analytic hierarchy process, Fuzzy evaluation, Transportation safety supervision, Henan province.

\section{INTRODUCTION}

Henan Province is located in the central part of China, with convenient transportation and obvious geographical advantages. Therefore, establishing a well-developed transportation network is the only way to revitalize Henan Province in the future. In 2020, the target length of the expressway in Henan Province is 8,020 km with the density of $480 \mathrm{~km} / \mathrm{km}^{2}$. By then, the 17 municipalities in Henan Province can form a well-developed road network and gradually form a fast, efficient, safe and convenient urban traffic road network[1,2]. Faced with such a huge transportation network, a severe test was put forward for the traffic safety supervision of Henan Province. Therefore, to study the current situation of traffic and transportation safety supervision in Henan Province and to establish an effective safety supervision system are important foundations to ensure the sustainable economic development and achieve rapid social development in Henan Province. Research on the current state of transportation safety supervision is a comprehensive subject that integrates evaluation, prediction and management. The research aims to further strengthen transportation safety and lay a solid foundation for promoting rapid economic development. In the economic and social development process of most provinces in China, transportation plays an important role, but it also exposes many problems. Therefore, research on the current situation of safety supervision in the transportation industry is an important way to realize the rational allocation of traffic safety supervision resources in the region, the construction of the evaluation system and the improvement of the supervision system.

Feng et al.[3] started by analyzing the positioning of comprehensive supervision in China, analyzed the main problems in the current comprehensive supervision of the transportation industry, and put forward suggestions such as establishing a comprehensive supervision organization system for industrial production safety. Li et al. [4] comprehensively analyzed the main problems of the current safety supervision in China's transportation industry,summarized and discussed the safety management methods and supervision modes of various transportation departments in China, and finally proposed a new idea of the whole process dynamic cycle safety 
supervision mode. Based on the construction of the safety management structure model of the transportation industry, Zhong et al.[5] studied the current situation of safety management of the transportation industry and its existing problems and put forward corresponding countermeasures and suggestions. The above content has studied various aspects of the current status of safety supervision of China's transportation industry, pointed out the outstanding problems in this field, and put forward corresponding countermeasures and suggestions, which are useful for improving the current safety supervision of China's transportation industry and the level of safety supervision Provides important research background. However, the above studies did not analyze relevant statistical data in combination with the specific survey data of the country's transportation industry.

Based on the safety supervision questionnaire survey of the competent departments of the transportation industry in Henan Province, this study combined the analytic hierarchy process and the fuzzy evaluation method to establish an evaluation model for the current situation of transportation safety supervision, and evaluate the current situation of safety supervision of the transportation industry in Henan Province. On this basis, summarizing the problems existing in the process of traffic safety supervision in Henan Province, the problems in the process of traffic safety supervision in Henan Province are summarized in order to realize the government's timely mastery of safety supervision and to improve the efficiency of the government and enterprises in transportation supervision.

\section{STATUS DESCRIPTION}

According to China's current transportation safety supervision system, and combined with the actual situation in Henan Province, the current traffic safety supervision status of Henan Province mainly involves four aspects: the overall situation of the transportation authorities at all levels, the basic situation of safety production of grass-roots safety production, the current status of the main units of supervision and the level of supervision and safety production service capacity of each unit. Therefore, in this paper, based on the above four supervision statuses, and according to the suggestions of each unit on the third-party evaluation of safety supervision, a questionnaire was designed to meet the safety supervision state of the transportation authorities in Henan Province.

\section{DATA SOURCE}

To fully investigate the current situation of traffic and transportation safety supervision in Henan Province, the relevant questionnaires were issued to 18 provincial municipalities, 10 provincial municipalities and relevant units directly under the Office. The contents of the questionnaire included the overall situation of the transportation authorities at all levels, the basic situation of safety production at the grass-roots level, the current status of the supervision entities of each unit, the level of supervision and the safety production service capacity of each unit, and the suggestions of each unit on the third-party evaluation of safety supervision. Most of the people who filled out the questionnaire were full-time employees of the safety production supervision department, and the proportion of department heads and leaders in charge of safety reached more than $68 \%$ of the people filled out. In addition, in the questionnaires, the safety management department accounted for $50 \%$ and the transportation management department reached more than $38 \%$, the number of valid questionnaires was 24 , and the efficiency reached more than $85 \%$. Therefore, the contents of the safety supervision questionnaire filled in by the transportation safety authority of Henan Province are not only true and reliable, but also highly authoritative. According to the specific situation of the questionnaire, this paper analyzed the current situation of the safety production supervision of the transportation industry in Henan Province from four aspects: the overall situation, the basic situation of safety production, the current situation of supervisory institutions and supervision level, and service capacity of the safety production.

\section{SAFETY SUPERVISION INDEX SYSTEM}

According to the safety survey questionnaire of the competent department of the transportation industry in Henan Province, the current status of traffic safety supervision in Henan Province is set as the target level. The four indicators of overall status of traffic safety supervision of each unit, the current status of the grass-roots production, the current status of the main body of supervisory and the current status of the level of supervision and service capacity of safety production are set as the criterion level. The four first-level indicators in the evaluation model mainly include the current situation of the level of traffic safety supervision and production safety service capacity of units at all levels, the overall status of traffic safety supervision, the current status of the basic foundation of safety production and the current status of the main body of traffic safety supervision. Among them, the overall status of traffic safety supervision of units at all levels includes self-evaluation of the overall traffic safety situation in the region under its jurisdiction, the areas with more safety hazards in the traffic industry under its jurisdiction and the number of commendations received in the last three years in the area of traffic safety production. Units at all levels of traffic safety production grass-roots foundation status includes the number of transport enterprises in the region under their jurisdiction, the professional category of transport enterprises with a high rate of production safety standards, the region under their jurisdiction in the past three years due to production safety issues were accountable, the 
number of employees in the field of transportation to obtain a safety officer certificate, the number of deaths due to traffic production safety accidents and areas of transport safety accidents. The status of the main units of traffic safety supervision at all levels include the establishment of the production safety committee in each unit, the frequency of regular meetings of the production safety committee, the development and issuance of the work responsibilities of the production safety committee, the content of transport safety supervision and other units cross, the development of the list of powers and responsibilities of various departments, the last three years and other units to carry out special rectification activities in traffic safety, the establishment of transport safety emergency equipment library In the past three years, the committee has established a system of safety contingency plans for transportation emergencies, established joint working mechanisms with other units on safety, adopted information technology in the management of official documents, regularly supervised and assessed the safety management responsibilities of subordinate industry management departments, set long-term transportation safety management goals and regularly held special meetings on safety production to hear reports on the work of relevant units on safety production. The current situation of the level of traffic safety supervision and production safety service capacity of units at all levels includes the assessment of the performance of transport safety supervision, the evaluation of the performance assessment in transport safety supervision and the main factors considered in the performance assessment and evaluation process indicators.

\section{MODEL ESTABLISHMENT AND BASIC PRINCIPLES}

This paper integrated analytic hierarchy process(AHP) and fuzzy evaluation method to establish the evaluation model of transportation safety supervision. The analytic hierarchy process $[6,7,8]$ can determine the weight coefficients of various indicators in the evaluation model. It can divide all the factors in the problem into a clear and orderly layer, making complex problems simpler. Fuzzy evaluation method $[9,10,11,12]$ is a mathematical method that allows comprehensive evaluation and quantitative study fuzzy phenomena affected by multiple factors $[13,14]$. This paper combined the two methods to evaluate the current status of traffic and transportation safety supervision in Henan Province. First, the weight of each indicator in the evaluation system by using the analytic hierarchy process. Then fuzzy evaluation is performed according to the objective actual situation, and the evaluation result is finally obtained $[15,16]$.

\section{TRAFFIC SAFETY SUPERVISION EVALUATION}

\subsection{Construction of Judgment Matrix}

According to the safety survey questionnaire of the competent department of the transportation industry in Henan Province, four indicators were selected at the criterion level in the hierarchical evaluation model, namely, the overall status indicator of traffic safety supervision of each unit, the status indicator of the grass-roots production, the status indicator of the supervisory entity and the supervision Indicators of current level and the capacity of safety production service. In this paper, 25 relevant factors were selected in the factor layer, and the judgment matrix constructed from the above indicators is shown in Table 1 5.

Table 1. Judgment matrix of criterion layer B on target layer $\mathrm{A}$

\begin{tabular}{llllll}
\hline$A$ & $B_{1}$ & $B_{2}$ & $B_{3}$ & $B_{4}$ & $W$ \\
\hline$B_{1}$ & 1 & 3 & 5 & 5 & 0.57076 \\
$B_{2}$ & $1 / 3$ & 1 & 3 & 2 & 0.23003 \\
$B_{3}$ & $1 / 5$ & $1 / 5$ & 1 & 1 & 0.090882 \\
$B_{4}$ & $1 / 5$ & $1 / 2$ & 1 & 1 & 0.10833 \\
$\lambda_{\max }=3.954, C I=-0.015243, C R=-0.016937<0.10$
\end{tabular}

Table 2. Judgment matrix of factor layer to criterion layer $B_{l}$

\begin{tabular}{lllll}
\hline$B_{1}$ & $C_{11}$ & $C_{12}$ & $C_{13}$ & $W$ \\
\hline$C_{11}$ & 1 & 2 & 1 & 0.4126 \\
$C_{12}$ & $1 / 2$ & 1 & 1 & 0.25992 \\
$C_{13}$ & 1 & 1 & 1 & 0.32748 \\
$\lambda_{\max }=3.954, C I=-0.026811, C R=-0.04625<0.10$ \\
\hline
\end{tabular}


Table 3. Judgment matrix of factor layer to criterion layer B2

\begin{tabular}{|c|c|c|c|c|c|c|c|c|c|c|c|c|c|c|}
\hline$B_{1}$ & $C_{21}$ & $C_{22}$ & $C_{23}$ & $C_{24}$ & $C_{25}$ & $C_{26}$ & $C_{27}$ & $C_{28}$ & $C_{29}$ & $C_{210}$ & $C_{211}$ & $C_{212}$ & $C_{213}$ & $W$ \\
\hline$C_{21}$ & 1 & 3 & 2 & 1 & 1 & 1 & 2 & 2 & 2 & 2 & 2 & 1 & 2 & 0.1212 \\
\hline$C_{22}$ & $1 / 3$ & 1 & $1 / 2$ & 1 & 1 & 1 & $1 / 2$ & $1 / 2$ & $1 / 2$ & 1 & 1 & $1 / 2$ & 1 & 0.050682 \\
\hline$C_{23}$ & $1 / 2$ & 2 & 1 & 2 & 2 & 2 & 1 & 1 & 1 & 1 & 2 & 2 & 3 & 0.10745 \\
\hline$C_{24}$ & 1 & 1 & $1 / 2$ & 1 & 1 & 1 & $1 / 2$ & $1 / 2$ & 1 & 1 & 1 & 1 & 1 & 0.063487 \\
\hline$C_{25}$ & 1 & 1 & $1 / 2$ & 1 & 1 & 1 & $1 / 2$ & $1 / 2$ & 1 & 1 & 1 & $1 / 2$ & 1 & 0.059247 \\
\hline$C_{26}$ & 1 & 1 & $1 / 2$ & 1 & 1 & 1 & $1 / 2$ & $1 / 2$ & 1 & 1 & 1 & $1 / 2$ & 1 & 0.059247 \\
\hline$C_{27}$ & $1 / 2$ & 2 & 1 & 2 & 2 & 2 & 1 & 1 & 1 & 1 & 2 & $1 / 2$ & 2 & 0.090766 \\
\hline$C_{28}$ & $1 / 2$ & 2 & 1 & 2 & 2 & 2 & 1 & 1 & 1 & 1 & 2 & $1 / 2$ & 2 & 0.090766 \\
\hline$C_{29}$ & $1 / 2$ & 2 & 1 & 1 & 1 & 1 & 1 & 1 & 1 & 1 & 1 & $1 / 2$ & 1 & 0.069234 \\
\hline$C_{210}$ & $1 / 2$ & 1 & 1 & 1 & 1 & 1 & 1 & 1 & 1 & 1 & 1 & $1 / 2$ & 1 & 0.065473 \\
\hline$C_{211}$ & $1 / 2$ & 1 & $1 / 2$ & 1 & 1 & 1 & $1 / 2$ & $1 / 2$ & 1 & 1 & 1 & $1 / 2$ & 1 & 0.05475 \\
\hline$C_{212}$ & 1 & 2 & $1 / 2$ & 1 & 2 & 2 & 2 & 2 & 2 & 2 & 2 & 1 & 2 & 0.11427 \\
\hline$C_{213}$ & $1 / 2$ & 1 & $1 / 3$ & 1 & 1 & 1 & $1 / 2$ & $1 / 2$ & 1 & 1 & 1 & $1 / 2$ & 1 & 0.053421 \\
\hline \multicolumn{15}{|c|}{$\lambda_{\max }=13.4753, C I=0.039605, C R=0.025388<0.10$} \\
\hline
\end{tabular}

Table 4. Judgment matrix of factor layer to criterion layer $B_{3}$

\begin{tabular}{llllllll}
\hline$B_{3}$ & $C_{31}$ & $C_{32}$ & $C_{33}$ & $C_{34}$ & $C_{35}$ & $C_{36}$ & $W$ \\
\hline$C_{31}$ & 1 & 1 & 1 & $1 / 2$ & $1 / 2$ & $1 / 2$ & 0.11316 \\
$C_{32}$ & 1 & 1 & $1 / 2$ & 1 & $1 / 3$ & 1 & 0.11796 \\
$C_{33}$ & 1 & 2 & 1 & 3 & 1 & 1 & 0.21229 \\
$C_{34}$ & 2 & 1 & $1 / 3$ & 1 & $1 / 2$ & $1 / 2$ & 0.11796 \\
$C_{35}$ & 2 & 3 & 1 & 2 & 1 & $1 / 2$ & 0.21229 \\
$C_{36}$ & 2 & 1 & 1 & 2 & 2 & 1 & 0.22633 \\
$\lambda_{\max }=6.3776, C I=0.07554, C R=0.060899<0.10$ & & \\
\hline
\end{tabular}

Table 5. Judgment matrix of factor layer to criterion layer $B_{3}$

\begin{tabular}{lllll}
\hline$B_{4}$ & $C_{41}$ & $C_{41}$ & $C_{41}$ & $W$ \\
\hline$C_{41}$ & 1 & 2 & 2 & 0.49339 \\
$C_{41}$ & $1 / 2$ & 1 & $1 / 2$ & 0.1958 \\
$C_{41}$ & $1 / 2$ & 2 & 1 & 0.31081 \\
$\lambda_{\max }=3.056, C I=0.026811, C R=0.046225<0.10$ \\
\hline
\end{tabular}

The consistency calculation showed that all the judgment matrices in the hierarchical evaluation model have passed the consistency test requirements, and all the judgment matrices were valid matrices and the weight coefficients meet the requirements.

\subsection{System Fuzzy Comprehensive Evaluation}

According to the 4 indicators at the criterion layer and 25 indicators at the factor level in the hierarchical evaluation model, combined with the effective questionnaires, the investigations of the transportation authorities at all levels in Henan Province were fuzzy evaluated. The comment collection used 4 levels, namely $\mathrm{V}=\left[V_{1}, V_{2}, V_{3}, V_{4}\right]$; respectively represent 4 levels of excellent, good, general, and poor. The fuzzy evaluation of each index corresponding to this evaluation model is shown in Table 6. 
Table 6. Index ratings about stratification evaluation model of safety supervision status

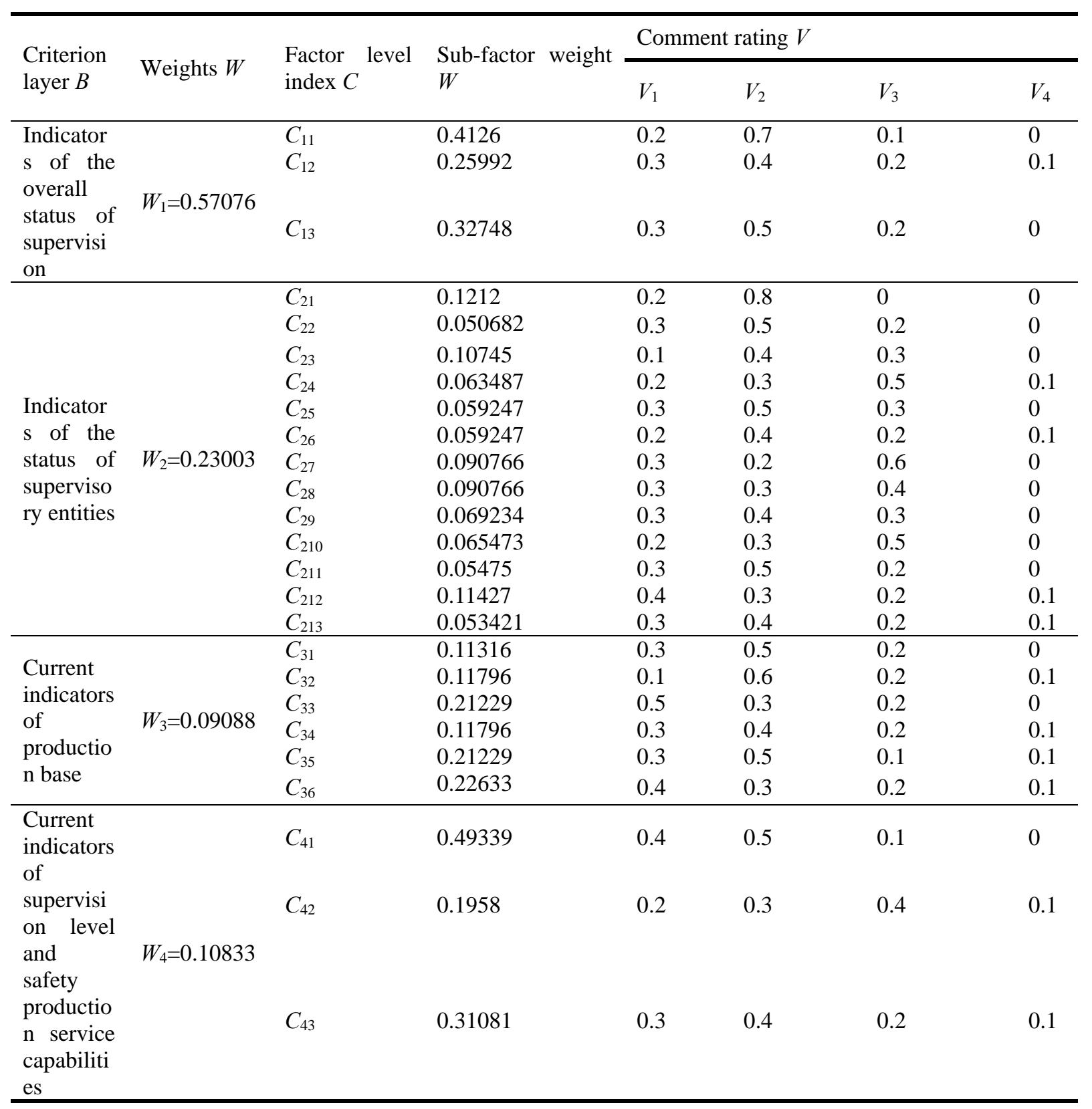

\subsection{Calculating the Total Score of the System}

According to the mathematical model (7) in the fuzzy evaluation method and the data in the table, the evaluation matrix of each index of the available factor layer were calculated, that were the fuzzy comment $N_{i}$ $(\mathrm{i}=1,2,3,4)$, the results are as follows:

$N_{1}=(0.2587,05564,0.15874,0.0260)$

$N_{2}=(0.2590,0.4134,0.2925,0.0290)$

$N_{3}=(0.3415,0.4134,0.1788,0.6750)$

$N_{4}=(0.3298,0.4298,0.1898,0.0507)$

The system evaluation matrix was calculated from the fuzzy evaluation formula (6) and the fuzzy comment $N_{i}$, which was the final fuzzy comment result:
$M=W N=(0.2590,0.4134,0.2925,0.0290)$

Finally, the relevant weight $F^{T}=(100,90,80,70)$ was determined, and the total score of the fuzzy evaluation system was calculate by:

$S=M F^{T}=88.536$

The total score of the fuzzy evaluation of the system was 88.536, which showed that the current traffic safety supervision status of Henan Province is in a good condition. This reflects that under the current traffic safety supervision system, the competent departments of the transportation industry in Henan Province at all levels can better perform their own supervisory duties, making the current transportation work under control. However, it also indicates that there are indeed problems in the current safety supervision work in Henan Province. 
According to the specific situation of the investigation, the annual safety funds and vehicle equipment of most transportation departments in Henan Province cannot meet the requirements. In addition, nearly half of the counties and cities have unclear divisions between the content of transportation safety supervision and the supervision of other units. The above situation shows that the current traffic and transportation safety supervision work in Henan Province needs to be further improved and strengthened.

\section{CONCLUSION}

1) Based on the feedback from the survey questionnaire of the competent department of the transportation industry in Henan Province, and combined with the actual status of the transportation industry in Henan Province, a hierarchical evaluation model for the current status of transportation safety supervision was established, and the various indicators in the model and their weight coefficients were determined and clear structure.

2) Through the comprehensive analytic hierarchy process and fuzzy evaluation method, the total score of the system was finally determined to be 88.536 , which shows that the current traffic safety supervision status of Henan Province is a in good condition. However, the supervision of traffic and transportation safety in Henan Province needs to be further improved and strengthened.

\section{ACKNOWLEDGMENTS}

This work was financially supported by Henan Transportation Technology Project fund.

\section{REFERENCES}

[1] Yu Hao. Thoughts on Perfecting the Supervision System of China Transportation Industry [J].China Economic \& Trade Herald, 2013(9):49-51.

[2] Yang Xiaoyu. Research on Henan province highway transportation and its import on regional economic development [D].Shenyang: Liaoning University,2015.

[3] Feng Wenwen, Li Zhiqiang. Analysis on Status of Comprehensive Supervision of Safety Production in Transportation Industry and Countermeasures [J].Science and Technology \& Innovation, 2017(9):1-3.

[4] Li Zhiqiang, Chen Jiding, Tian Jian. Status quo of Safety Administration for Transportation Construction Engineering and Its Administration Modes [J].China Safety Science Journal, 2008(7):74-79.

[5] Zhong Pengyun, Yin Hui. Analysis and Countermeasures of Safety Management in Traffic
Transport Industry of China [J]. Safety and Environmental Engineering, 2018, 25(01):105-108.

[6] Feng Changgen, Li Jie, Li Shengcai. Application of the analytical hierarchy process method to the safety science research in China [J]. Journal of Safety and Environment, 2018,18(06):2126-2130.

[7] Wang Bing, Xie Hongli, Ren Hongyang, et al. Assessment for phytoremediation plant growth in petroleum contaminated soil via analytic hierarchy process [J]. Journal of Safety and Environment, 2019, 19(03):985-991.

[8] Du Yihang, Fang Weining, Wang Lijun, et al. A non-technical skills-oriented synthetic evaluation model for the railway train drivers based on the analytic hierarchy process [J]. Journal of Safety and Environment, 2019,19(03):887-892.

[9] Yan Wenyu, Li Chenyang, Wang Jinghong, et al. Fuzzy evaluation for the chlorination process accident risk based on the immune mechanism [J].Journal of Safety and Environment, 2018,18(01):11-16.

[10] Wang Yan, Yang Zhangchi, Huang Guozhong, et al. Risk severity analysis of the failure liability of the passenger vehicle brake system based on the fuzzy comprehensive evaluation [J]. Journal of Safety and Environment, 2019,19(02):391-398.

[11] Ma Dong, Meng Qingbin, Gu Xuejing, et al. Emission control technology assessment of heavy duty diesel vehicles based on comprehensive fuzzy evaluation [J]. Journal of Safety and Environment, 2019,19(03):947-953.

[12] Wu Peng, Chen Faming, Liu Jian,et al. Assessment and forecast of the snowy drift on the hazard degrees on the highways based on the fuzzy comprehensive assessment method [J]. Journal of Safety and Environment, 2017, 17(06):2273-2276.

[13] Tang Jia, Dong Xin, Li Fang,et al. On the evaluation of the collision risk in the flying formation based on the FAHP [J]. Journal of Safety and Environment, 2017, 17(05):1641-1644.

[14] Qi Xiaogui, Chen Yizhou. An improved risk assessment method in regard to the cross-tunnel landslide geological zones[J]. Journal of Safety and Environment, 2016,16(05):37-40.

[15] Jin Chunling, Wang Yunxin, Gong Li. Risk assessment of sudden water pollution in Lanzhou section of Yellow River based on fuzzy hierarchy evaluation method [J]. Journal of Safety and Environment, 2018, 18(01):363-368. 
[16] Zhang Dongming, Bai Yongjie, et al. Evaluation and prediction of the geological hazards in the deep-buried long tunnel project through fuzzy-hierarchical analysis [J]. Journal of Safety and Environment, 2018,18(01):50-55.

[17] Li Lingjuan, Dou Kun. Research on the Consistency of the Judgment Matrix in AHP [J]. Computer Technology and Development, 2009,19(10).

[18] Huang Decai,Xu Lin. Proportion criteria and method for building comparison matrices in the analytic hierarchy process [J]. Control and Decision, 2002, 17(4):484-486.

[19] Liu Weiguo. MATLAB programming tutorial M].Beijing: China Water \& Power Press,2010.

[20] Wang Shuang, Li Zhiping, Xin Qian, et al. Overall safety assessment of fuzzy comprehensive evaluation method [J]. Modern Electronics Technique, 2019(11):82-86. 